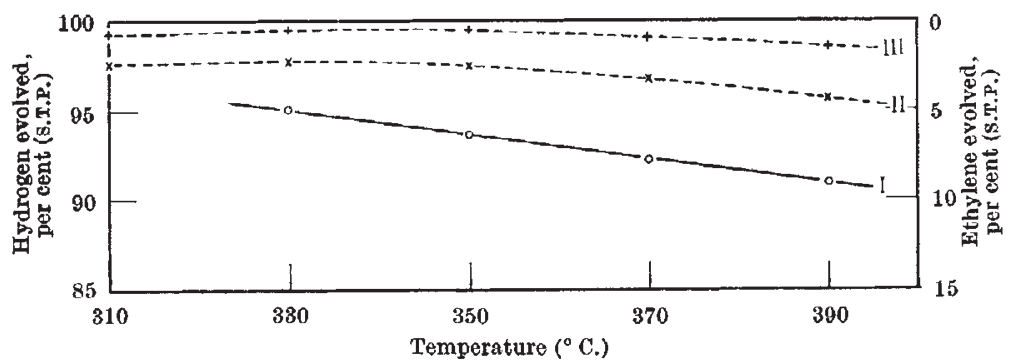

Fig. 2. Behaviour of zinc oxide catalysts. Ethyl alcohol feed, $0 \cdot 204 \mathrm{ml} / \mathrm{min}$. catalyst, zine oxide type $A, 0.4 \mathrm{gm}$. $20-28 \mathrm{mesh}$. I $(0)$, Normal catalyst; II $(x)$, radioactive, $20 \mathrm{mc} / \mathrm{gm}$; ; III $(+)$, radioactive, $52.4 \mathrm{mc} / \mathrm{gm}$.

polar substrates. On the other hand, various simple plots of similar values obtained from unsaturated fatty acid esters with polar substrates, correlating chain length or number of double bonds, yield surprisingly little information ${ }^{1-4}$. In the course of gas-liquid chromatographic examination of the methyl esters of the fatty acids of marine oils the retention-time data of a number of identified unsaturated fatty acids examined by different workers $^{1,4-8}$, all using polyester substrates, were plotted on semilog

hydrogen/ethylene ratio in the reaction products, which is a function of the radioactivity of the catalyst. Work is in progress to investigate the catalytic behaviour of different catalysts ( $p$-type semiconductors) to see if it is possible by irradiation to introduce any Fermi-level shifting which may increase the dehydration reaction under similar reaction conditions.

This communication is published by permission of the Director, Mines Branch, Department of Mines and Technical Surveys, Ottawa.

Mineral Sciences Division,

M. Donato

Department of Mines and Technical Surveys, Ottawa.

1 Clark, R. W., and Gibson, E. J., Nature, 180, 140 (1958).

2 Taylor, E. H., J. Chem. Edue., 36, 396 (1959).

3 Brown, T., and Maxim, I., Nature, 192, 598 (1961).

4 Bragg, R. H., Morritz, F. L. Holtzman, R., Feng, P. Y., and Pizzarello, F., Wright Air Development Center Tech. Rep., 59 286 (1959).

${ }^{5}$ Wolkenstein, F. F., Adv. in Catalysis, 12, 121 (1960).

- Kon, W. H., Moore, G. E. and Taylor, E. H., Oak Ridge Nat. Lab. Prog. Rep. 2584, 17 (1958).

${ }^{7}$ Roginsky, S. Z., Krylov, O. V. and Fokina, E. A., Bull. Acad. Sci. U.S.S.R., Div. Chem. Sci., 442 (1957).

${ }^{8}$ Adkins, H., and Lazier, W. A., J. Amer. Chem. Soc., 48, 1671 (1925).

- Garner, W. E., Adv. in Catalysis, 9, 169 (1957).

\section{pH Effects in the Radiolysis of Aquo-Organic Systems}

THE experimental data given in our recent communication ${ }^{1}$ on this subject refer to the systems (I) $0.1 M$ HCOONa- $0.01 M \quad \mathrm{Na}_{2}{ }^{14} \mathrm{CO}_{3} ;$ (II) $0.1 M$ $\mathrm{H}^{14} \mathrm{COONa}-0.01 M \mathrm{Na}_{2} \mathrm{CO}_{3}$. The solutions were prepared with $\mathrm{NaHCO}_{3}$ and were adjusted to $p \mathrm{H} 11$ with sodium hydroxide prior to irradiation.

Warren M. Garrison

BOYD M. WEEKS

Sibyl Cole

Lawrence Radiation Laboratory,

Crocker Laboratory,

University of California,

Berkeley 4, California.

${ }^{1}$ Garrison, W. M., Weeks, B. M., and Cole, S., Nature, 193, 1291 (1962).

\section{CHEMISTRY}

\section{Structure and Retention Time in the Gas-liquid Chromatography of Unsatur- ated Fatty Acids on Polyester Substrates}

Ir is generally accepted that plots of $\log _{10}$ retention time in the gas-liquid chromatography of the longer chain normal saturated fatty acid methyl esters against the number of carbon atoms in the fatty acid ohain give a straight line with both non-polar and paper against the number of carbon atoms in the fatty acid chain. Despite the fact that a number of differing polyester substrates were used, the resulting plots showed a surprising overall similarity. This suggested that the key to the relation of the plotted points lay in the structural position of the methyleneinterrupted double bond systems in the fatty acid chains in the case of the polyethylenic fatty acids, and in the position of the isolated double bonds in the monoethylenic fatty acids, rather than in the type of polyester.

The following hypothesis is therefore advanced. In plots of $\log _{10}$ retention time of ethylenically unsaturated fatty acids versus number of carbon atoms, where polyester phases are used, parallel straight lines can be drawn between those points corresponding to fatty acids of the same number of methylene-interrupted double bonds, or of single double bonds, when the number of carbon atoms beyond the double bond farthest removed from the carboxyl group, including the terminal methyl group, is the same.

A corollary to this hypothesis is that the lines are parallel to that derived from certain of the commonly occurring monoethylenic fatty acids, namely, octadec9-enoic, eicos-11-enoic, and docos-13-enoic, and not necessarily parallel to the plot of the saturated fatty acids. Since two or more of these are normally present in most natural lipids, the basis for plotting other materials is readily available. The general observation may also be made that the precise nature of the polyester is relatively unimportant (ef. ref. 6), facilitating comparison of data from various authors.

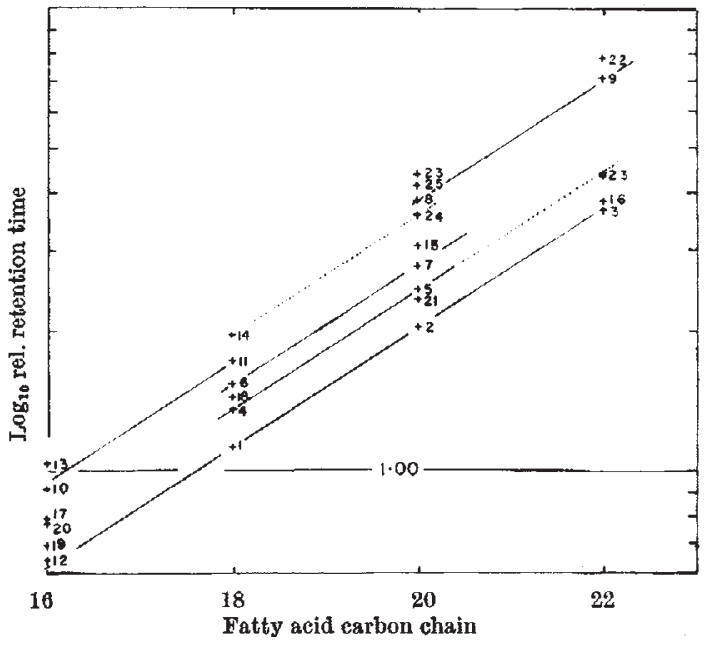

Fig. 1. Point plot of relative retention time data from Table 1, with parallel lines correlating fatty acid structure 